\title{
Hubungan Lingkar Perut dan Tekanan Darah Karyawan STIKES Yarsi Mataram
}

\author{
Zaenal Arifin ${ }^{1 *}$, Gladeva Yugi Antari ${ }^{2)}$, Melati Inyati Albayani ${ }^{3)}$ \\ Email: z.arifin70@gmaill.com \\ ${ }^{1)}$ STIKES YARSI MATARAM, PRODI NERS \\ 2) STIKES YARSI MATARAM, PRODI KEBIDANAN JENJANG D.III \\ 3) STIKES YARSI MATARAM, PRODI KEPERAWATAN JENJANG D.III
}

\begin{abstract}
ABSTRAK
Diperkirakan sekitar $20-25 \%$ populasi dewasa di dunia memiliki sindrom metabolik dan memiliki resiko 2 kali untuk mengalami serangan jantung dan stroke. Peningkatan prevalensi sindroma metabolik terkait dengan peningkatan komponen sindroma metabolik seperti diabetes mellitus, obesitas sentral, hipertensi dan dislipidemia. Berdasarkan data Riskesdas tahun 2013 menunjukkan adanya peningkatan pada diabetes mellitus menjadi $2,1 \%$, obesitas sentral menjadi $26,6 \%$, hipertensi menjadi $9,5 \%$, dan penyakit jantung meningkat menjadi $1,5 \%$. Salah satu komponen sindrom metabolik yang prevalensi menunjukkan peningkatan adalah hipertensi. Hipertensi merupakan faktor dari obesitas. Tujuan penelitian ini adalah untuk mengetahui hubungan lingkar perut dan tekanan darah. Desain penelitian observasional yang bersifat korelatif dengan pendekatan cross-sectional yang dilakukan di Stikes Yarsi Mataram pada bulan Desember 2018 sampai Januari 2019. Sampel penelitian adalah karyawan Stikes Yarsi Mataram sebanyak 51 orang menggunakan tehnik purpossive sampling. Secara statistik terdapat hubungan bermakna antara lingkar perut dan tekanan darah. Kesimpulan penelitian ini bahwa Hasil uji statistik lingkar perut pada tekanan darah sistol diperoleh nilai $\mathrm{p}<0,001$, berarti terdapat hubungan lingkar perut dengan tekanan darah sistol. Hasil uji statistik lingkar perut pada tekanan darah diastol diperoleh nilai $\mathrm{p}<0,001$, berarti terdapat hubungan lingkar perut dengan tekanan darah diastol.
\end{abstract}

Kata kunci: Lingkar Perut, Tekanan Darah.

\begin{abstract}
It is estimated that around $20-25 \%$ of the adult population in the world has metabolic syndrome and has 2 times the risk of having a heart attack and stroke. Increased prevalence of metabolic syndrome is associated with an increase in components of metabolic syndrome such as diabetes mellitus, central obesity, hypertension and dyslipidemia. Based on Riskesdas data in 2013 showed an increase in diabetes mellitus to $2.1 \%$, central obesity to $26.6 \%$, hypertension to $9.5 \%$, and heart disease increased to $1.5 \%$. One component of the metabolic syndrome whose prevalence shows an increase is hypertension. Hypertension is a factor of obesity. The purpose of this study was to determine the relationship of abdominal circumference and blood pressure. The observational study design was correlative with a cross-sectional approach conducted at Stikes Yarsi Mataram in December 2018 to January 2019. The sample of the study were 51 people at Stikes Yarsi Mataram using purposive sampling technique. Statistically there is a significant relationship between abdominal circumference and blood pressure. The conclusion of this study is that the results of the abdominal circumference statistical test on systolic blood pressure obtained $\mathrm{p}$ value $<0.001$, meaning there is a relationship between abdominal circumference and systolic blood pressure. Abdominal circumference statistical test results in diastolic blood pressure obtained $\mathrm{p}$ value $<0.001$, meaning there is a relationship between abdominal circumference and diastolic blood pressure.
\end{abstract}

Keywords: Abdominal Circumference; Blood Pressure. 


\section{A. LATAR BELAKANG}

Sindrom metabolik merupakan sekelompok faktor risiko yang meningkatkan risiko penyakit jantung dan masalah kesehatan lainnya, seperti diabetes dan stroke. Istilah metabolisme mengacu pada proses biokimia yang terlibat dalam fungsi normal tubuh. Sindrom metabolik menurut AHA[1] adalah beberapa faktor resiko yang meningkatkan resiko terjadinya penyakit jantung, diabetes mellitus, dan stroke. Kriteria untuk mengidentifikasi sindrom metabolik ini adalah adanya 3 (tiga) faktor resiko dari beberapa faktor resiko sebagai berikut yaitu obesitas sentral, kadar trigliserida lebih dari $150 \mathrm{mg} / \mathrm{dL}$, Kadar kolesterol HDL $<40 \mathrm{mg} / \mathrm{dL}$, tekanan darah tinggi (> 130/85 mmHg), kadar glukosa darah puasa $>100 \mathrm{mg} / \mathrm{dL}$.

Menurut International Diabetes Federation [2] diperkirakan sekitar 20-25\% populasi dewasa di dunia memiliki sindrom metabolik dan memiliki resiko 2 kali untuk mengalami serangan jantung dan stroke.

Peningkatan prevalensi sindroma metabolik terkait dengan peningkatan komponen sindroma metabolik seperti diabetes mellitus, obesitas sentral, hipertensi dan dislipidemia. Berdasarkan data Riskesdas [3] menunjukkan bahwa prevalensi diabetes mellitus sebesar $1,1 \%$, penyakit jantung sebesar $0,9 \%$, hipertensi sebesar 7,6\%, dan obesitas sentral sebesar 18,8\%. Sedangkan data Riskesdas tahun 2013 menunjukkan adanya peningkatan pada diabetes mellitus menjadi $2,1 \%$, obesitas sentral menjadi $26,6 \%$, hipertensi menjadi $9,5 \%$, dan penyakit jantung meningkat menjadi $1,5 \%$. Salah satu komponen sindrom metabolik yang prevalensi menunjukkan peningkatan adalah hipertensi.

Menurut WHO hipertensi menjadi masalah kesehatan masyarakat global dan penyebab utama morbiditas dan mortalitas [4]. Peningkatan prevalensi hipertensi diperkirakan menyebabkan 7,5 juta kematian, dan dilaporkan bertanggung jawab atas hampir 13\% dari semua kematian dan 3,7\%. Menurut American Heart Association penduduk Amerika berusia diatas 20 tahun yang menderita hipertensi telah mencapai angka hingga 74,5 juta jiwa, dan sekitar 90-95\% kasus tidak diketahui penyebabnya[1].

Berdasarkan data WHO prevalensi hipertensi di Asean pada kelompok dewasa usia diatas 25 tahun yaitu $37.7 \%$ pada laki-laki dan $34.9 \%$ pada perempuan. Data WHO menunjukkan bahwa diantara negara-begara Asean, Indonesia merupakan salah satu negara dengan prevalensi hipertensi cukup tinggi yaitu 42.7\%, dan diantara negara Asean, Indonesia menduduki urutan ke-2 setelah Myanmar [4].

Data Riskesdas tahun 2018 menunjukkan bahwa hipertensi menjadi salah satu masalah kesehatan dengan prevalensi yang cukup tinggi yaitu sebesar 34,1\% meningkat sebesar 8,3\% jika dibandingkan dengan hasil Riskesdas tahun 2013. Prevalensi hipertensi di Propinsi Nusa Tenggara Barat berdasarkan hasil pengukuran tekanan darah pada penduduk usia diatas 18 tahun sekitar 22,2\%. Prevalensi hipertensi berdasarkan terdiagnosis tenaga kesehatan dan pengukuran terlihat meningkat dengan bertambahnya umur.

Menurut Kemenkes [5] tekanan darah tinggi atau hipertensi merupakan suatu kondisi yang ditandai adanya peningkatan tekanan darah sistolik lebih dari $140 \mathrm{mmHg}$ dan tekanan darah diastolik lebih dari $90 \mathrm{mmHg}$ pada dua kali pengukuran dengan selang waktu lima menit dalam keadaan cukup istirahat atau tenang.

Faktor resiko hipertensi terdiri dari faktor yang dapat diubah dan faktor yang tidak dapat diubah. Faktor yang tidak dapat diubah atau dikontrol antara lain adalah umur, jenis kelamin, riwayat keluarga, genetik. Sedangkan faktor resiko yang dapat diubah atau dikontrol diantaranya adalah kebiasaan merokok, konsumsi garam, konsumsi lemak jenuh, penggunaan jelantah, kebiasaan konsumsi minuman beralkohol, kurang aktifitas fisik, stres, penggunaan estrogen dan obesitas [5].

Obesitas merupakan salah satu faktor resiko hipertensi yang dapat dikontrol atau dikendaikan. Obesitas atau kegemukan merupakan suatu kondisi adanya akumulasi lemak yang berlebihan yang ditandai dengan 
IMT lebih dari $30 \mathrm{Kg} / \mathrm{M} 2$ [6].

Berdasarkan data Riskesdas tahun 2018 proporsi obesitas juga menunjukkan peningkatan sebesar 7\%, yang sebelumnya sebesar $14,8 \%$ pada tahun 2013 menjadi 21,8\% pada tahun 2018. Proporsi obesitas di Propinsi Nusa Tenggara Barat (NTB) sebesar 15\% berdasarkan hasil pengukuran indeks masa tubuh (IMT) pada penduduk usia diatas 18 tahun. Sedangkan proporsi obesitas sentral berdasarkan hasil pengukuran lingkar perut pada penduduk usia diatas 15 tahun adalah sebesar 31,0\%, dan proporsi obesitas sentral di Propinsi NTB sebesar $25 \%$.

Hubungan obesitas dengan hipertensi dapat disebabkan adanya peningkatan berat badan dan adipositas kronis dapat menyebabkan adanya perubahan neuro-hormon dan adaptasi pada sistem kardiovaskular. Perubahan neurohormonal yang terjadi antara lain adalah aktivasi sistem renin angiotensin-aldosteron dan aktivasi sistem saraf sismpatik [7].

Menurut Duvnjak [8] peningkatan akumulasi lemak visceral merupakan prediktor kuat terjadinya hipertensi arteri. Mekanisme terjadinya hipertensi dikaitkan dengan obesitas sentral akibat adanya peningkatan aktivasi sistem saraf simpatik. Stimulasi simpatis kronis memfasilitasi keseimbangan energi dan stabilisasi berat badan pada pola makan yang berlebihan. Selain itu peningkatan kadar asam lemak vena portal dimungkinkan juga berpengaruh terhadap terjadinya hipertensi dengan obesitas visceral. Peningkatan konsentrasi asam lemak vena portal memiliki efek pressor yang signifikan, yang dipengaruhi adanya peningkatan saraf simpatik.

Penelitian terkait obesitas dan hipertensi yang telah dilakukan diantaranya adalah hasil penelitian Sulastri, Elmatris, Ramadhani [9] di Kota Padang didapatkan bahwa lebih dari separuh penderita hipertensi mengalami obesitas $(56,6 \%)$ dan obesitas sentral $(54,9 \%)$. Dan menunjukkan adanya hubungan yang bermakna antara obesitas dengan kejadian hipertensi $(\mathrm{p}=0,025)$ dan obesitas sentral dengan kejadian hipertensi $(\mathrm{p}=0,002)$. Hasil penelitian lain tentang lingkar abdomen demgam tekanan darah yang dilakukan Sari, Lipoeto, Herman [10] menunjukkan rerata lingkar abdomen karyawan laki-laki sebesar $84,50 \pm 9,50 \mathrm{~cm}$, karyawan perempuan sebesar $83,57 \pm 8,98 \mathrm{~cm}$, dan didapatkan data bahwa sebanyak $14,13 \%$ karyawan memiliki tekanan darah tinggi (hipertensi). Berdasarkan uji statistik menunjukkan terdapat hubungan signifikan antara lingkar perut dengan tekanan darah sistolik pada subjek laki-laki dan perempuan $(\mathrm{p}<0,01$ dan $\mathrm{p}<0,05)$.

Berdasarkan hal tersebut maka peneliti tertarik untuk mengidentifikasi ukuran lingkar perut dan tekanan darah karyawan STIKES Yarsi Mataram.

\section{B. METODE PENELITIAN}

Penelitian ini merupakan penelitian observasional yang bersifat korelatif dengan pendekatan cross-sectional. Penelitian ini dilakukan di Stikes Yarsi Mataram. Penelitian dilaksanakan Desember 2018-Januari 2019. Sampel penelitian ini adalah karyawan Stikes Yarsi Mataram sebanyak 51 orang. Data yang diperoleh dari hasil penelitian dilakukan uji normalitas dengan uji Fisher dan dianalisis menggunakan uji t-test.

\section{HASIL DAN PEMBAHASAN}

Uji normalitas dilakukan sebelum dilakukan uji pada tekanan darah sistol dan diastol. Uji normalitas menggunakan uji KolmogorovSminov karena data $\geq 50$ sampel, hasil uji menunjukkan bahwa data tekanan darah sistol $(\mathrm{p}=0,064)$ berdistribusi normal karena nilai $\mathrm{p}>0,05$. Selanjutnya dilakukan uji $t$ tidak berpasangan. Data tekanan diastole $\mathrm{p}<0,05$, maka dilakukan transformasi data. Hasil transformasi data masih berdistribusi tidak normal, jadi uji yang dilakukan menggunakan mean whitney.

Hasil Analisis bivariat hubungan lingkar perut dengan tekanan darah sistol pada responden di STIKES Yarsi Mataram dapat 
dilihat pada table berikut ini :

Tabel 1. Hubungan Lingkar Perut Dengan Tekanan Darah Sistol Karyawan STIKES Yarsi Mataram Tahun 2018

\begin{tabular}{|c|c|c|c|}
\hline $\begin{array}{c}\text { Tekanan } \\
\text { Darah Sistol }\end{array}$ & N & Rerata \pm SD & p value \\
\hline Normal & 46 & $86,2 \pm 8,6$ & \multirow{2}{*}{$<0,001$} \\
\hline Tinggi & 5 & $130 \pm 3,5$ & \\
\hline
\end{tabular}

Berdasarkan Tabel 1 diatas rerata lingkar perut pada responden yang memiliki tekanan darah sistol normal jauh lebih tinggi dibandingkan dengan responden yang memiliki tekanan darah sistol tinggi. Rerata lingkar perut pada responden yang memiliki tekanan darah sistol normal adalah $86,2 \pm 8,6 \mathrm{mmHg}$ dan nilai rerata lingkar perut pada responden yang memiliki tekanan darah sistol tinggi adalah 130 $\pm 3,5 \mathrm{mmHg}$. Hasil uji statistik lingkar perut pada tekanan darah sistol diperoleh nilai $\mathrm{p}<0,001$, berarti terdapat hubungan lingkar perut dengan tekanan darah sistol.

Hasil Analisis bivariat Hubungan lingkar perut dengan tekanan darah diastol pada responden di STIKES Yarsi Mataram dapat dilihat pada tabel berikut ini :

Tabel 2. Hubungan Lingkar Perut Dengan Tekanan Darah Diastol Karyawan STIKES Yarsi Mataram Tahun 2018

\begin{tabular}{|c|c|c|c|}
\hline $\begin{array}{c}\text { Tekanan } \\
\text { Darah Diastol }\end{array}$ & N & Rerata \pm SD & p value \\
\hline Normal & 44 & $85,6 \pm 8,37$ & \multirow{2}{*}{$<0,001$} \\
\hline Tinggi & 7 & $101,8 \pm 3,5$ & \\
\hline
\end{tabular}

Berdasarkan Tabel 2 diatas rerata lingkar perut pada responden yang memiliki tekanan darah diastol normal jauh lebih tinggi dibandingkan dengan responden yang memiliki tekanan darah diastol tinggi. Rerata lingkar perut pada responden yang memiliki tekanan darah diastol normal adalah $85,6 \pm 8,3 \mathrm{mmHg}$ dan nilai rerata lingkar perut pada responden yang memiliki tekanan darah diastol tinggi adalah $101,8 \pm 3,5 \mathrm{mmHg}$. Hasil uji statistik lingkar perut pada tekanan darah diastol diperoleh nilai $\mathrm{p}<0,001$, berarti terdapat hubungan lingkar perut dengan tekanan darah diastol.

Hasil penelitian ini sejalan dengan penelitian yang dilakukan Hafid [11] tentang hubungan lingkar pinggang dengan tekanan darah dan asam urat menunjukkan adanya hubungan yang bermakna antara lingkar pinggang terhadap tekanan darah $(\mathrm{p}=0,014)$ dan terdapat hubungan yang bermakna antara lingkar pinggang dengan asam urat $(\mathrm{p}=0,004)$. Pada penelitian ini didapatkan bahwa tidak ada hubungan antara lingkar perut dengan tekanan darah. Hal ini sejalan dengan penelitian yang dilakukan oleh Sari, Lipoeto, Herman [10] menunjukkan adanya hubungan yang signifikan antara lingkar abdomen dengan tekanan darah sistolik pada subyek laki-laki dan perempuan $(\mathrm{p}<0,01$ dan $\mathrm{p}<0,05)$, namun tidak terdapat hubungan lingkar abdomen dengan tekanan darah diastolik baik pada laki-laki maupun perempuan $(\mathrm{p}>0,05)$

Lingkar perut atau abdominal circumference merupakan parameter klinis yang penting untuk menilai risiko perkembangan sindrom metabolik. Pengukuran lingkar perut dilakukan untuk mengetahui ada tidaknya obesitas abdominal atau obesitas sentral. Obesitas abdominal sangat berpengaruh terhadap kejadian penyakit kardiovaskular dan diabetes melitus, serta kejadian sindroma metabolik. Lingkar perut dapat menggambarkan adanya timbunan lemak di dalam rongga perut. Semakin panjang lingkar perut menunjukkan adaya timbunan lemak yang berlebihan dalam rongga perut. Penimbunan lemak yang berlebihan dalam rongga perut dapat memicu timbulnya penyakit jantung dan diabetes mellitus. Untuk pria dewasa Indonesia lingkar perut normal adalah $92.0 \mathrm{~cm}$ dan untuk wanita $80.0 \mathrm{~cm}$ [12]. Pengukuran distribusi lemak tubuh dapat dilakukan dengan pengukuran lingkar pinggang dan rasio lingkar pinggang dan lingkar pinggul. Pengukuran antropometri obesitas abdominal dengan menggunakan ukuran lingkar pinggang dan rasio lingkar pinggang pinggul memiliki hubungan yang lebih kuat dengan faktor resiko metabolik dan penyakit kardiovaskuler [13].

Menurut Canoy et al [14] indeks obesitas abdominal lebih konsisten dan memiliki prediksi yang kuat terhadap penyakit jantung koroner. 
Pengukuran obesitas abdominal dapat digunakan untuk menilai risiko penyakit jantung koroner yang terkait dengan obesitas baik pada laki-laki maupun perempuan yang relatif sehat. Akumulasi lemak visceral dapat mendasari profil metabolisme yang merugikan akibat obesitas. Pengukuran lingkar pinggang dan rasio lingkar pinggang dan lingkar pinggul merupakan indikator untuk mengetahui adanya penimbunan lemak pada abdominal, dan pengukuran lingkar pinggang dan rasio lingkar pinggang-lingkar pinggul terbukti lebih baik daripada pengukuran indeks massa tubuh (IMT) untuk mengidentifikasi resiko tinggi terkena penyakit aterosklerosis.

\section{KESIMPULAN}

Berdasarkan hasil uji statistik lingkar perut pada tekanan darah sistol diperoleh nilai $\mathrm{p}<0,001$, berarti terdapat hubungan lingkar perut dengan tekanan darah sistol dan hasil uji statistik lingkar perut pada tekanan darah diastol diperoleh nilai $\mathrm{p}<0,001$, berarti terdapat hubungan lingkar perut dengan tekanan darah diastol.

\section{DAFTAR PUSTAKA}

[1] AHA. (2015). What Is Metabolic Syndrome?

[2] International Diabetes Federation (2006). The IDF consensus worldwide definition of the metabolic syndrome.

[3] Depkes (2008). Riset Kesehatan Dasar 2007.

[4] WHO. (2013). High Blood Pressure. Globl and Regional Overview.

[5] Kemenkes RI. (2014). Infodatin. Hipertensi. Pusat Data dan Informasi Kementerian Kesehatan.

[6] WHO. (2018). Obesity and overweight, https://www.who.int/.

[7] Tune, J.D., Goodwill, A.G., Sassoon, D.J., Mather, K. (2017). Cardiovascular Consequences of Metabolic Syndrome. Transl Res. $183: 57-70$

[8] Duvnjak, L., Bulum, T, Metelko, Z. (2008). Hypertension and Metabolic Syndrome. Diabetologia Croatia. 37-4

[9] Sulastri, D., Elmatris., Ramadhani, R. (2012).Hubungan Obesitas Dengan Kejadian Hipertensi Pada Masyarakat Etnik
Minangkabau Di Kota Padang. Majalah Kedokteran Andalas No.2. Vol.36.

[10] Sari, M.K., Lipoeto, N.I., Herman, R.B. (2016). Hubungan Lingkar Abdomen (Lingkar Perut) dengan Tekanan Darah. Jurnal Kesehatan Andalas. 5 (2)

[11] Hafid, M.A. (2018). Hubungan Antara Lingkar Pinggang Terhadap Tekanan Darah Dan Asam Urat Di Dusun Sarite'ne Desa Bili-Bili. Journal Of Islamic Nusing. Volume 3 Nomor 1.

[12] Thamaria, N. (2017). Penilaian Status Gizi. PPSDM Kesehatan. Kemenkes.

[13] Koning, Lawrence de, Anwar T. Merchant, Janice Pogue, and Sonia S. Anand. Waist Circumference and Waist-To-Hip Ratio as Predictors of Cardiovascular Events: MetaRegression Analysis of Prospective Studies. 2007. European Heart Journal (2007) 28, 850-856.

[14] Canoy et al. (2007). Body Fat Distribution and Risk of Coronary HeartDisease in Men and Women in the European ProspectiveInvestigation Into Cancer and Nutrition in Norfolk CohortA PopulationBased Prospective Study. Circulation. 116:2933-2943. 